\title{
PENGARUH KOMPENSASI DAN KEPEMIMPINAN TERHADAP KEPUASAN KERJA DAN DAMPAKNYA TERHADAP KUALITAS PELAYANAN PEGAWAI PADA KANTOR DINAS KEBUDAYAAN DAN PARIWISATA PROVINSI PAPUA
}

\author{
Patmer Frits Apomfires 2 \\ Email: patmerfrits@gmail.com \\ Yasir Attamimi ${ }^{2}$ \\ Email: yasir.attamimi@feb.uncen.ac.id \\ 1-2 Fakultas Ekonomi dan Bisnis Universitas Cenderawasih
}

\begin{abstract}
Abstraksi :
Melihat Provinsi Papua yang kaya akan sumber daya alam, keragaman budaya, dan keindahan pariwisata yang sangat melimpah, membuat pemerintah perlu memfokuskan pengelolaan pada bidang Budaya dan Pariwisata agar kekayaan tersdebut tetap dilestarikan dengan baik dan terjaga. Penelitian ini menggunakan menggunakan metode penelitian: kualitatif dan kuantitatif. Hasil penelitian: (1) Kompensasi berpengaruh positif dan signifikan terhadap kepuasn kerja. (2) Kepemimpinan berpengaruh positif dan signifikan terhadap kepuasn kerja. (3) Kompensasi berpengaruh positif dan signifikan terhadap Kualitas pelayanan. (4) Kepemimpinan berpengaruh positif dan signifikan terhadap kualitas pelayanan. (5) Kepuasn kerja berpengaruh positif dan signifikan terhadap kualitas pelayana. (6) Berdasarkan analisis sobel test, Kompensasi berpengaruh terhadap Kualitas pelayanan melalui kepuasn kerja. (7) Berdasarkan analisis sobel test, Kepemimpinan tidak berpengaruh terhadap Kualitas pelayanan melalui kepuasan kerja.
\end{abstract}

Kata Kunci : Kompensasi, Kepemimpinan, Kepuasan Kerja, Kualitas Pelayanan.

\section{PENDAHULUAN}

\section{A. Latar Belakang}

Provinsi Papua dengan keberagaman budaya dan yang tersebar luas pada 29 kabupaten/kota dengan kurang lebih 250 etnis serta keadaan alam, flora, dan fauna, sebagai karunia Tuhan Yang Maha Esa perlu diperhatikan dan dilindungi, dikembangkan untuk kepentingan pembangunan, khususnya pembangunan di bidang kebudayaan dan pariwisata. Namun hal ini tidak di dukung dengan peresentase angka pengetahuan dan pemahaman para penduduk yang masih cukup rendah. Berdasarkan UU 15 tahun 2009 menjelaskan bahwa Pelayanan Publik merupakan kegiatan atau rangkaian kegiatan dalam rangka pemenuhan kebutuhan pelayanan sesuai dengan peraturan perundang-undangan bagi setiap warga negara dan penduduk atas barang, jasa, dan/atau pelayanan administratif yang disediakan oleh penyelenggara pelayanan publik. Dalam hal ini pemerintah memiliki peran yang cukup penting untuk meningkatkan kualitas pelayanan dari para penyelenggara pelayanan yang sudah diatur oleh pemerintah dalam undang-undangan yang berlaku.

Sesuai dengan tugas dan tanggung jawab yang di wewenangkan dari pemerintah terhadap Penyelenggara pelayanan publik maka, Tugas utama yang di jalankan Dinas Kebudayaan dan Pariwisata Provinsi Papua adalah memberikan sosialisasi, bimbingan, serta penyuluhan-penyuluhan terkait dengan pelestarian dan pengembangan dari nilai-nilai Kebudayaan dan pariwisata terhadap masyarakat.

Namun beda halnya yang terjadi pada tahun 2020 silam, setelah bencana besar dunia (covid-19) yang terjadi dan berdampak bagi seluruh lapisan masyarakat, mengakibatkan semua kegiatan sosial dan perekonomian kacau. Banyak hal juga berubah pada kinerja dan pelayanan yang di berikan pemerintah bagi masyarakat melaluai penyelenggarapenyelenggara pelayanan yang sudah di tetapkan.Dalam hal ini Kompensasi menjadi salah satu kebutuhan utama yang dibutuhkan oleh seorang pegawai selaku manusia untuk memenuhi kebutuhan hidupnya agar bisa meningkatkan kualitas hidupnya dan dapat memberikan kontribusi yang baik bagi perusahaan 
Sejak jaman kuno Kepemimpinan telah di bahas oleh pada cerdik pandai. Contoh dasar Kepemimpinan pertama kali Kepemimpinan menjadi faktor penting dalam upayah dalam menghadapi perubahan keorganisasian, melakukan sebuah respon terhadap krisis dan menggunakan seluruh pontensi organisasi dalam rangka pertumbuhan dan tercapainya tujuan organisasi, keyakinan kuat terhadap cita-cita bersama, dan sinergi seluruh komponen yang ada di dalamnya (Syahrul 2015).

Menurut Wexley dan Yukl 2003 (dalam Sujati, 2018), kepuasan kerja merupakan generalisasi sikap-sikap terhadap pekerjaannya. Dengan demikian dapat di simpulkan bahwa, Kepuasan Seorang karyawan merupakan salah satu respon perasaan atas apa yang diterima dan dirasakannya sehingga berdampak juga atas hasil yang akan di berikan pegawai tersebut.

\section{B. Tujuan Penelitian}

a) Untuk mengetahui apakah ada pengaruh Kompensasi terhadap Kepuasan Kerja pada kantor Dinas Kebudayaan dan Pariwisata Provinsi Papua.

b) Untuk mengetahui apakah ada pengaruh Kepemimpinan terhadap Kepuasan Kerja pada kantor Dinas Kebudayaan dan Pariwisata Provinsi Papua.

c) Untuk mengetahui apakah ada pengaruh Kompensasi terhadap Kualitas Pelayanan pada kantor Dinas Kebudayaan dan Pariwisata Provinsi Papua

d) Untuk mengetahui apakah ada pengaruh Kepemimpinan terhadap Kualitas Pelayanan pada kantor Dinas Kebudayaan dan Pariwisata Provinsi Papua.

e) Untuk mengetahui apakah ada pengaruh Kepuasan Kerja terhadap Kualitas Pelayanan pada kantor Dinas Kebudayaan dan Pariwisata Provinsi Papua.

f) Untuk mengetahui apakah ada pengaruh Kompensasi terhadap Kualitas Pelayanan melalui Kepuasan kerja pada kantor Dinas Kebudayaan dan Pariwisata Provinsi Papua.

g) Untuk mengetahui apakah ada pengaruh Kepemimpinan terhadap Kualitas Pelayanan melalui Kepusasan kerja pada kantor Dinas Kebudayaan dan Pariwisata Provinsi Papua.

\section{KAJIAN TEORI}

1. Sumber Daya Manusia

Manajemen Sumber Daya Manusia merupakan pengelolaan dan pendayagunaan sumber daya yang ada pada seseorang. Pengelolaan dan pendayagunaan tersebut harus dikembangkan secara maksimal di dalam dunia kerja untuk mencapai tujuan organisasi dan pengembangan individu pegawai (Anwar Mangkunegara, 2013). Menurut Simamora (dalam Sutrisno, 2015), manajemen sumber daya manusia adalah pendayagunaan, pengembangan, peniliaian, pemberian balas jasa dan pengelolaan individu anggota organisasi atau kelompok pekerja.

2. Kompensasi

Kompensasi adalah semua pendapatan yang berbentuk uang baik yang langsung maupun yang tidak langsung sebagai suatu imbalan atas jasa yang diberikan kepada perusahaan. kompensasi adalah sesuatu yang diterima para karyawan sebagai balas jasa atas prestasinya dalam melaksanakan tugas (Kadar Nurjaman, 2014). Indikator Kompensasi Pada Penelitian ini, yaitu:
a) Gaji
b) Upah
c) Insentif
d) Tunjangan
e) Fasilitas

3. Kepemimpinan

Kepemimpinan secara harfian berasal dari kata pimpin. Kata pimpin mengandung pengertian mengarahkan, membina atau mengatur, menuntun dan juga menunjukkan ataupun mempengaruhi. Menurut Kartono (2016) kepemimpinan adalah kemampuan mempengaruhi orang lain, bawahan, atau kelompok, mengarahkan tingkah laku bawahan atau orang lain untuk mencapai tujuan organisasi atau kelompok. Indikator kepempinan Penelitian ini, Yaitu:
a) Pendengar
b) Komunikator 

c) Motivator
d) Kontroler
e) Jujue

4. Kepuasan Kerja

Kepuasan kerja merupakan salah satu elemen yang cukup penting dalam organisasi. Hal ini disebabkan kepuasan kerja dapat mempengaruhi prilaku seseorang dalam bekerja seperti malas, rajin, produktif yang sangat penting dalam sebuah perusahaan/organisasi. Menurut Sutrisno(2017) Kepuasan kerja adalah perasaan senang atau tidak senang pegawai dalam memandang dan menjalankan pekerjaanya. Indikator Kepuasan Kerja pada Penelitian kali ini, yaitu:
a) Pekerjaan Itu sendiri
b) Atasan
c) Teman Kerja
d) Promosi
e) Gaji

5. Kualitas Pelayanan

Bedasarkan pada UU 25 Tahun 2009 menjelaskan bahwa Pelayanan Publuk merupakan kegiatan atau rangkaian kegiatan dalam rangka pemenuhan kebutuhan pelayanan sesuai dengan peraturan perundangundangan bagi setiap warga negara dan penduduk atas barang, jasa, dan/atau pelayanan administratif yang disediakan oleh penyelenggara pelayanan publik. Pelayanan publik yang selanjutnya disebut Penyelenggara adalah setiap institusi penyelenggara negara, korporasi, lembaga independen yang dibentuk berdasarkan undang-undang untuk kegiatan pelayanan publik, dan badan hukum lain yang dibentuk semata-mata untuk kegiatan pelayanan publik. Jasa publik dalam ketentuan ini adalah jasa yang dihasilkan oleh badan usaha milik negara/badan usaha milik daerah yang mendapat pelimpahan tugas untuk menyelenggarakan pelayanan publik. Indikator Kualitas pelayanan pada Penelitian ini, yaitu:
a) Kepentingan Umum
b) Kesamaan Hak
c) Keterbukaan
d) Keprofesionalan
e) Partisipatif

\section{METODE PENELITIAN}

\section{A. Populasi dan sampel}

Populasi sendiri di bedakan menjadi dua yaitu finit dan infinit. Ciri, karakter, dan kualitas itu yang di namakan sebagai variabel (Nazir, 2015). umlah keseluruhan populasi pegawai pada Dinas Kebudayaan dan Pariwisata Provinsi Papua ada sebanyak 181 orang pegawai. Pengambilan sampel untuk penelitian menurut Suharsimi Arikunto (2010: 112), jika subjeknya kurang dari 100 orang sebaiknya diambil semuanya, jika subjeknya besar atau lebih dari 100 orang dapat diambil 10-15\% atau 20-25\% atau lebih. Jadi sampel pada penelitian ini adalah $(181-35 \%=63,35)$. Jadi jumlah sampel yang di ambil pada penelitian ini adalah "63" individu Pegawai.

\section{B. Jenis dan Sumber Data}

Jenis data yang di gunakan pada Penelitian ini adalat data Kuantitatif. Data Kuantitatif dalam penelitian ini merupakan data perhitungan angka dari kuisioner yang telah di isi dan dilengkapi sampel yang telah di tentukan. Sedangkan sumber data pada Penelitian ini sendiri terdiri dari dua yaitu, data primer yang di kumpulkan langsung dari pada pegawai dan data sekunder yang terdiri dari data yang tersedia pada objek penelitian, jurnal penelitian terdahulu, buku-buku teori bersangkutan, dan situs internet atau artikel yang berkenaan dengan penelitian yang dilakukan.

\section{Teknik Pengumpulan Data}

Pada Penelitian ini peneliti mengumpulkan data dengan menggunakan studi lapangan yang di antaranya wawancara yang dilakukan langsung dengan para pegawai dan pemimpin, Observasai di mana peneliti turun langusung pada kantor yang dan melakukan engamatan situasi dan keadaan yang berlangsung, dan peneliti meggunakan metode Pembagian Angket/Kuisioner yang di bagikan kepada para pegawai untuk di isi.

Selain itu teknik pengumpulan data yang di gunakan yaitu studi pustaka di mana peneliti menelih informasi dari berbagai sumber-sumber dalam sumber-sumber tertulis yang sudah ada, seperti jurna ilmiah, buku referensi, dan teoriteori yang berdangutan dengan penelitian yang dilakukan. 


\section{Metode Analisis Data}

Pada penelitian ini di gunakan analisi pendekatan Struktural Equstion Model (SEM) berbasis Partial Least Square (PLS). Pada analisis ini menggunakan dua tahap, yaitu :

a) Tahap pertama adalah analisis yang bernama uji Measurement model, yang bertujuan untuk menguji validitas dan reliabilitas konstruk dari masing-masing indikator. Pada tahap ini terdiri dari Uji Instrumen (Outer Model atau Measurement Model) yang di antaranya Uji Valiiditas Konvergen, Uji Validitas Deskriminan, Uji Reliability dan Average Variance Extracted (AVE), Cronbach Alpha.

b) Tahap kedua adalah analisis dengan melakukan pengujian Struktural model yang bertujuan untuk mengetahui ada atau tidaknya pengaruh antara variabel/korelasi antara konstruk-konstruk yang diukur dengan uji t pada PLS Pengujian Model Struktural (Inner Model) terdiri dari, Uji R-Square, Inner VIF Vlaues (Multikolinearitas), Uji Path Coefficient, Uji Hipotesis.

\section{HASIL DAN PEMBAHASAN}

\section{A. Gambaran Umum Objek}

Dinas Kebudayaan dan Pariwisata merupakan salah satu bidang di dalam urusan pemerintah yang memerhatikan dan mengontrol seluruh unsur yang berkaitan dengan urusan pariwisata dan kebudayaan pada suatu daerah. Peraturan Daerah Provinsi Papua Nomor 19 tahun 2016 tentang Pembentukan Perangkat Daerah Provinsi Papua dan Peraturan Gubernur Papua Nomor. 43 Tahun 2016 Tentang Organisasi dan Tata Kerja Dinas Kebudayaan dan Pariwisata Provinsi Papua, yaitu menyelenggarakan urusan pemerintahan di bidang Kebudayaan dan Pariwisata serta tugas-tugas lainnya yang diberikan oleh Gubernur.

\section{B. Hasil Pengujian Hipotesis}

Dasar pengujian hipotesis dalam penelitian ini adalah nilai yang terdapat pada output result for inner weight. Hipotesis digunakan dengan cara membandingkan nilai signifikan dan juga t statistic. Variabel berpengaruh jika nilai signifikan lebih rendah $<$ dari 0,05. Dan variable berpengaruh jika nilai t statistic $>$ dari t table.

\section{Gambar 1. 1 Hasil Pengujian Inner Model}

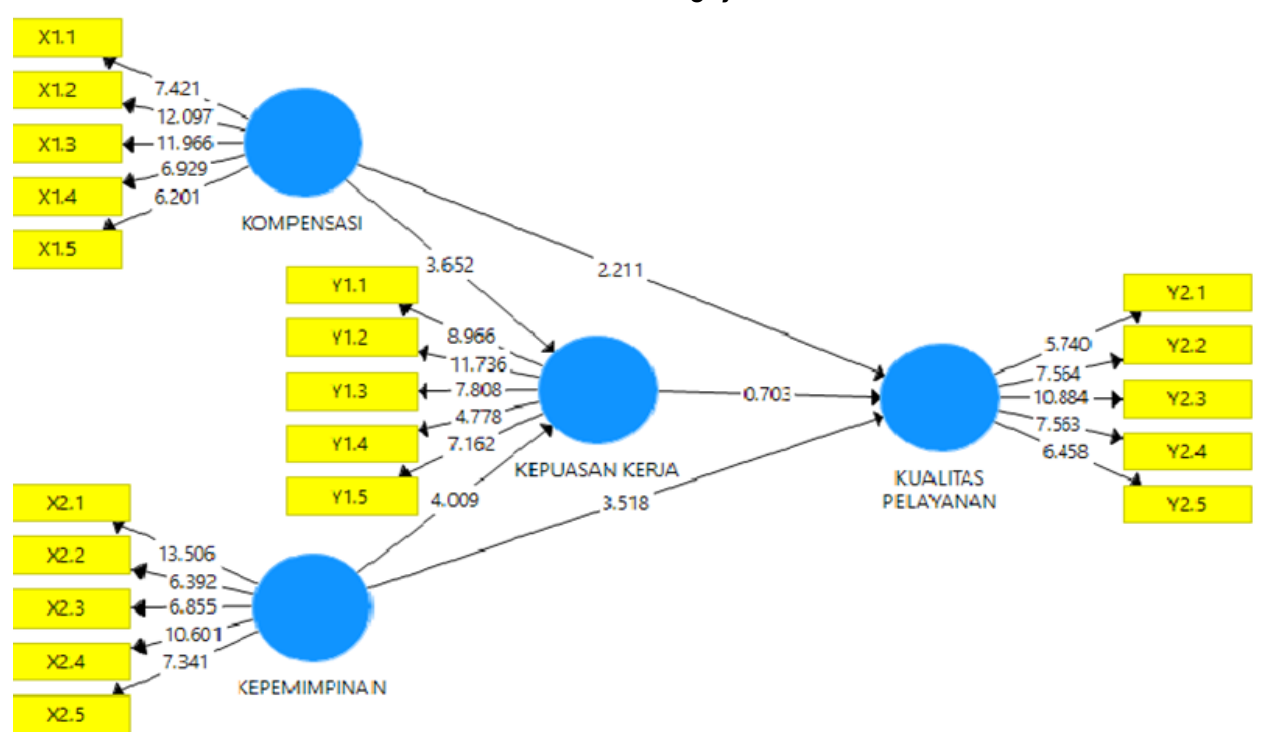

Pada Penelitian ini Variabel dapat di katakan Berpengaruh Positif dan signifikan apabila Nilai P-Value $<(0,05)$ dan TStatistik > dari T-Tabel.

a) Berdasarkan gambar di atas bahwa t statistic (3.652) lebih besar $>$ dari t tabel $(2,010)$ dan nilai P-Value $(0,000)$ kurang $>$ dari nilai standar $(0,05)$. Sehingga dapat disimpulkan Variabel Kompensasi Berpengaruh Signifikan terhadap Kepuasan Kerja. 
b) Berdasarkan gambar di atas bahwa t statistic $(4,009)$ lebih besar $>$ dari $t$ tabel $(2,010)$ dan nilai P-Value $(0,000)$ kurang > dari nilai standar $(0,05)$. Sehingga dapat disimpulkan Variabel Kepemimpinan Berpengaruh Signifikan terhadap Kepuasan Kerja.

c) Berdasarkan gambar di atas bahwa t statistic $(2,211)$ lebih besar $>$ dari $t$ tabel $(2,010)$ dan nilai P-Value $(0,027)$ kurang $>$ dari nilai standar $(0,05)$. Sehingga dapat disimpulkan Variabel Kompensasi Berpengaruh Signifikan terhadap Kualitas Pelayanan.

d) Berdasarkan gambar di atas bahwa t statistic (3.518) lebih besar $>$ dari t tabel $(2,010)$ dan nilai P-Value $(0,000)$ kurang > dari nilai standar $(0,05)$. Sehingga dapat disimpulkan Variabel Kepemimpinan Berpengaruh Signifikan terhadap Kualitas Pelayanan.

e) Berdasarkan gambar di atas bahwa t statistic $(0,703)$ lebih kecil < dari t tabel $(2,010)$ dan nilai P-Value $(0,483)$ lebih Besar $>$ dari nilai standar $(0,05)$. Sehingga dapat disimpulkan Variabel Kepuasan Kerja tidak berpengaruh Seignifikan Terhdap Kualitas Pelayanan.

f) Berdasarkan gambar di atas bahwa t statistic $(0,647)$ lebih kecil < dari t tabel $(2,010)$ dan nilai P-Value $(0,518)$ lebih besar $>$ dari nilai standar $(0,05)$. Sehingga dapat disimpulkan Variabel Kompensasi tidak berpengaruh signifikan terhadap Kualitas Pelayanan.

g) Berdasarkan gambar di atas bahwa t statistic $(0,606)$ lebih kecil < dari t tabel $(2,010)$ dan nilai P-Value $(0,545)$ lebih besar $>$ dari nilai standar $(0,05)$. Sehingga dapat disimpulkan VariabelKepemimpinan tidak berpengaruh signifikan terhdap Kualitas Pelayanan..

\section{Pembahasan}

a) Menurut Hasibuan (2016) Besar kecilnya kompensasi mencerminkan status, pengakuan, dan tingkat pemenuhan kebutuhan yang dinikmati oleh karyawan bersama keluarganya. Jika balas jasa yang diterimanya semakin tinggi, statusnya semakin baik, dan pemenuhan kebutuhan yang dinikimatinnya semakin banyak pula. Dengan demikian kepuasan kerjanya semakin baik. Dengan demikian yang menjadi tugas dan tanggung jawab utama pemimpin adalah untuk memberikan pemenuhan kebutuhan para pegawai dengan cara melihat kompensasi yang di berikan apakah sudah sesuai atau tidak. Jika para pegawai merasa kurang puas dengan balas jasa yang di terima dan kurang cukup untuk memenuhi kebutuhan hidupnya, maka dapat di pastikan bahwa para pegawai akan merasa tidak puas dan kinerjanya pun akan ikut menurun.

b) Menurut Made Nurcahyani dan Dewi Adyani (2016), Mengemukakan bahwa Tinggi atau rendahnya motivasi dan kepuasan kerja karyawan pada suatu perusahaan juga tergantung dari peranan pemimpin dalam perusahaan tersebut, kepemimpinan yang baik merupakan kunci dalam manajemen yang mempunyai peran penting dalam strategi dalam kelangsungan hidup suatu perusahaan.Dalam hal ini yang berperan penting untuk mengontrol dan membangun perasaan puas para pegawai adalah tugas seorang pemimpin, karena pemimpinlah berkuasa dan dapat di dengarkan oleh seluruh pegawai.

c) Menurut Umar (2002:16) kompensasi adalah sesuatu yang diterima karyawan sebagai balas jasa untuk kerja mereka. Selain sebagai balas jasa juga bisa memotivasi mereka dalam mencapai tujuan dari organisasi atau perusahaan.Kompensasi yang di berikan harus sesuai dengan pencapaian dan tanggung jawab yang di berikan kepada para pegawai dan harus memuaskan sesuai dengan harapan untuk pemenuhan kebutuhan dasar yang di perlukan, agar para pegawai merasa tingkat pelayanan dan kinerjanya masih dibutuhkan sehingga mereka akan tetap bertahan bahkan meningkatkan kualitas pelayahnannya.

d) Berdasarkan UU No 25 tahun 2009 (pasal 20) "Penyelenggara berkewajiban menyusun dan menetapkan standar pelayanna dengan memperhatikan kemampuan Penyelenggara, Kebutuhan masyarakat, dan kondisi lingkungan. Berdasrkan kutipan UU di atas bahwa ada beberapa tugas seorang pemimpin yang ditetapkan oleh pemerintah untuk menunjang pelayanan publik bagi masyarakat. Untuk itu pemimpin pada Kantor Dinas Kebudayaan dan Pariwisata Provinsi Papua harus memiliki tingkat koordinasi yang baik dengan para bawahannya termasuk melihat nilai kebutuhan masyarakat dan kondisi lingkungan di mana proses pelayanan tersebut berlangsung, agar para pegawai dapat di kontrol dan di koordinir dengan baik untuk memberikan kualitas pelayanan yang baik dan memuaskan.

e) Hal terkait dengan kualitas pelayanan yang di berikan oleh Kantor Dinas Kebudayaan Dan Pariwisata Provinsi Papua merupakan faktor penting yang harus di perhatikan, di mana tugas dan penetapan yang di tetapkan pada UU 25 tahun 2009 " Bahwa negara berkewajiban melayani setiap warga negara dan penduduk untuk memenuhi 
hak dan kebutuhan dasarnya dalam kerangka pelayanan publik". Dapat disimpulkan bahwa Kepuasan warga dan masyarakat adalah tanggung jawab utama pemerintah negara, dengan begitu dinas Kebudayaan dan Pariwisata harus lebih fokus untuk meningkatkan kualitas yang baik terhadap masyarakat.

f) Berdasarkan pada UU no 25 tahun 2009 (pasal 1) yang berbunyi "Pelayanan Publik adalah kegiatan atau rangkaian kegiatan dalam rangka pemenuhan kebutuhan pelayanan sesuai dengan peratuaran perundang-undangan bagi setiap warga negara dan penduduk. Melihat hal tersebut tentunya bukan berarti kepuasan kerja para pegawai akan tetap baik-baik saja dan memberikan kualitas pelayanan yang baik kepada masyarakat. Ini menjadi perhatian yang serius bagi pemimpin kantor untuk memberhatikan kompnensasi yang di berikan kepada para pegawai dengan berdasrkan tingkat kinerja dan tanggung jawab yang telah di kerjakan.

g) Berdasarkan UU no 25 tahun 2009 (pasal 1) yang berbunyi "Atasan satuan kerja penyelenggara adalah pemimpin satuan kerja yang membawahi secara langsung satu atau lebih satuan kerja yang melaksanakan pelayanna publik. Kualits pelayanan para pegawai perlu di perhatikan dan di kontrol oleh bapak Kepala Dinas Kebudayaan dan Pariwisata Provinsi Papua agar tetap memberikan pelayanan yang terbaik.

\section{PENUTUP}

\section{A. Simpulan}

Berdasarkan hasil penelitian dan pembahasan di atas, maka penelitian ini dapat menyimpulkan beberapa hal sebagai berikut:

a) Kompensasi memberikan pengaruh yang positf dan signifikan terhadap kepuasan kerja para pegawai.

b) Kepemimpinan memberikan pengaruh yang positif dan signifikan terhadap kepuasn kerja para pegawai.

c) Kompensasi memberikan pengaruh yang positif dan signifikan terhadap kualits pelayanan para pegawai.

d) Kepemimpinan memberikan pengaruh yang positif dan signifikan terhadap kualitas pelayanan para pegawai

e) Kepuasan kerja pegawai tidak memberikan pengaruh yang positif dan signifikan terhadap kualitas pelayanan para pegawai.

f) Tidak adanya pengaruh kompensasi terhadap kualitas pelayanan melalui kepusan kerja.

g) Tidak adanya pengaruh kepemimpinan terhadap kualitas pelayanan melalui kepusan kerja.

\section{B. Saran}

Berdasarkan simpulan di atas, maka saran-saran yang diajukan oleh penulis dalam penelitian ini adalah sebagai berikut:

a) Kepada Kepala Dinas Kebudayaan dan Pariwisata Provinsi Papua, Harus mencerminkan sifat dan peranan yang baik terhadap para pegawai agar mereka merasa puas karena merasa di perhatikan dan di hargai.

b) Kepada Kasubag Kepegawaian Kantor Dinas BudPar Provinsi Papua, agar melihat tingkat tanggung jawab pekerjaan dan tugas yang di selesaikan dan di kerjakan oleh para pegawai untuk di sesuaikan dengan pemberian balas jasa yang setimpal.

c) Untuk Penelitian selanjutnya, semoga penelitian ini dapat dijadikan sebagai bahan reverensi bagi para peneliti selanjutnya untuk melakukan penelitian yang sejalan dengan penelitian ini. 


\section{DAFTAR PUSTAKA}

Almigo, Nuzsep. 2004. Hubungan Antara Kepuasn Kerja Dengan Produktivitas Kerja Karyawan. Jurnqa PSYCHE. 1(1). 5060.

Anwar Prabu Mangkunegara, 2013, Manajemen Sumber Daya Manusia Perusahaan, Remaja Rosdakarya, Bandung.

Azhar, Muhammad Elfi, dkk. 2020. Pengaruh Disiplin Kerja dan Kompensasi Kepuasan Kerja Keryawan. Jurnal Humaniora. 4(1). 46-60.

Bangun, Wilson. 2012. Manajemen Sumber Daya Manusia. Jakarta: Erlangga.

Bashori. 2019. Kepemmpinan Tranformasional Kyai Pada Lembaga Pendidikan Islam.Jurnal Manajemen Pendidikan Islam. 3(2). $73-84$.

Ceswidarni, dkk. 2017. Pengaruh Kompentensi dan Kualitas Kerja Terhadap Prestasi Kerja Pegawai Di Kantor Kecamatan Kuranjani.n Jurnal Manajemen dan Kewirausahaan. 8(1). 1-6.

Chair Ummul, Hamka. 2018. Pengaruh Budaya Organisasi, Kepemimpinan, dan Motivasi terhasp Kualitas Pelayanan Mahasiswa (Studi Kasus Perguruan Tinggi Kabuten Maros). 1(2). 25-31.

Desseler, Gary. 2015. Manajemen Sumber Daya Manusia. Jakarta: PT INDEKS.

Elfi Azar, dkk. (2020). Pengaruh disiplin Kerja dan Kompensasi terhadap Kepuasn kerja Karyawan. 4(1). Jurnal Humaniora: Jurnal Ilmu Sosial, Ekonomi Dan Hukum: 46-60.

George 2012 (dalam Lie TF, dkk). 2018. Pengaruh kepuasn kerja Terhadap Kinerja karyawan melalui Motivasi pada CV.Union Event Planner. Agora. 6(1).

Harahap, Khair. 2019. Pengaruh Kepemimpuinan Danb Kompensasi Terhadap Ke[puasan Kerja Melalui Motivasi Kerja. Jurnal Ilmiah Magister Manajemen.2(1).

Hasmalawati, Restya. 2017. Hubungan Kualitas Kerjs Terhadap Motivasi Kerja Karyawan Di Puskesmas Paya Bakong Aceh. Jurnal Sains Psikologi. 6(2). 63-67.

Hasibuan,2012(dalamBabll,Sinta).https://sinta.unud.ac.id/uploads/dokumen_dir/56c54024d6a44fd207e32440b33df418.pdf/.

Hasibuan, Malayu S.P. 2016. Manajemen Sumber Daya Manusia. Edisi Revisi. Jakarta: Penerbit PT Bumi Aksara.

Hatta Muhammad, dkk. 2017. Pengaruh Gaya Kepemimpinan, Kerjasama Tim, dan Kompensasi Terhadap Kepuasn Kerja serta Dampaknya Terhadap Kinerja Karyawan PT. PLN (Persero) Wilayah Aceh. Jurnasl Magister Manajemen. 01(01). 70-80.

Hermawan Endang. 2020. Pengaruh Iklm Organisasi dan Pengembangan Karir terhadp Kepuasn Kerja Serta Dampaknya terhadap Kualutas Pelayanan. 1(2). 86-95.

Hidayat Anwar. 2021." Inner Model PLS SEM dalam SMARTPLS". https://www.statistikian.com/2021/04/inner-model-plssem-smart-pls.html/ di akses pada 29 Juni 2021. 
Hughes, R.L., Ginnet, R.C., dan Curphy, G.J. 2012. Leadership: Memperkaya Pelajaran dari Pengalaman, Edisi Ketujuh, Jakarta: Salemba Humanika.

Husein, Umar. 2014. Metode Penelitian untuk Skripsi dan Tesis Bisnis. Jakarta : PT.Raja Grafindo Persada.

Idrus, Muhammad. 2006. Implikasi Iklim Organisasi Terhadap Kepuasan Kerja Dan Kualitas Kehidupan Kerja Karyawan. Jurnal Psikologo Universitas Diponegoro. 3(1). 94-106.

James, Gibson, dkk. 1986. Organisasi Dan Manajemen. Jakarta: Penerbit Erlangga.

Kartono 2016 (Dalam Hasyim 2020). Kinerja Karyawan: Gaya kepemimpinan, Pengawasan Dan disiplin. Bekasi. Universitas Kali Malang.

Kasmir 2017 (dalam SE Wasito 2018. Customer Service Excellent. PT Raja Grafindo Persada. Depok.

Nurcahyani, Adnyani. 2016. Pengaruh Kompensasi Dan Motivasi Terhadap Kinaerja Karyawan DAENGAN Kepuasn kerja Sebagai Variabel Intervening.E-Jurnal Manajemen Unud. 5(1). 500-532.

Nurjaman, Kadar. (2014). Manajemen Personalia. Bandung : CV Pustaka Setia.

Prasada, Dodi. 2020. Pengaruh Etos Kerja Dan Kompensasi Teerhadap Komitmen Organisasi Pada DHL Logistik Di Jakarta. Jurnal IImiah, Manajemen Sumber Daya Manusia. 4(1). 51-59.

Republik Indonesia. 2009. Undang-undang Republik Indonesia Nomor 25 tahun 2009 :Tentang "Pe;ayanan Publik". Jakarta : Kementrian Riset, Teknologi, dan Pendidikan.

Risamasu, Ferdinand. 2017. Pengantar Manajemen. Medan: Penerbit Madenatera.

Rivaldo Yandra, Sri Langgeng. Pengaruh Kepemimpinan dan Motivasi Terhadap Kepuasan Kerja serta Dampaknya Terhadap Kualitas Kerja. Jurnal Dimensi. 9(3). 505-515.

Rustilah, Sri. 2018. Pengaruh Gaya Kepemimpinan Dan Kompensasi Terhadap Kepuasn Kerja Dan Kinerja Pegawai Tenaga Kontrak. Jurnal Of Managementv Review. 2(2). 219-222.

Santoso 2014 (dalam FGL Raja). HUBUNGAN MOTIVASI, LINGKUNGAN KERJA, KEPEMIMPINAN, DISIPLIN KERJA, DAN KINERJA KARYAWAN PT ASIANA TECHNOLOGIES LESTARY JAKARTA. Yogyakarta. e-Journal.

Sedarmayanti, HJ. 2010. Manajemen Sumber Daya Manusia "Reformasi Birokrasi dan Manajemen Pegawai Negeri Sipil". Bandung: PT Refika Aditama.

Simamora (dalam Sutrisno 2015). D Ratnasari 2017. "Bab II Manajemen Sumber Daya Manusia". http://eprints.polsri.ac.id/4177/3/BAB\%20Il.pdf/ Pada tahun 2011.

Smith, Kendall, dan Hulin 2006 (dalam Lumban Tobing 2015. Tinjauan Pustaka Bab II. http://ejournal.uajy.ac.id/8871/3/2MM02220.pdf/

Suharsimi Arikunto 2010. Prosedur Penelitian Suatu pendekatan Praktek. Jakarta: Rineka Cipta.

Sutrisno, Edy. 2017. Manajemen Sumber daya Manusia. Cetakan ke-9. Jakarta: Kencana 
Syahrul. 2015. Kepemimpinan Dan Inovasi Lembaga Pendidikan (Pengalaman Pondok Gontor VII Putra Sulawesi Tenggara). Jurnal Kajian Ilmu Pendidikan. 8(1). 394-708.

Thoha 2010 (Dalam Wardani 2016). Bab II Kajian Pustaka. http://repository.unpas.ac.id/15808/4/BAB\%202.pdf/.

Usman 2011 (dalam R ahmadiansah).2016. Pengaruh motivasi kerja dan kepuasan kerja terhadap kinerja guru SMK muhamadiah salatiga. Interdisciplinary Journal of Communication: 1(2).

Umar, Husein. 2001. Sumber Daya Manusia Dalam Organisasi. Jakarta: Gramedia Pustaka Utama.

Wexley, Yukl, 2003,(Dalam Sujati 2018). Kepuasan Kerja: Arti Penting, Faktor-faktor yang mempengaruhi, Dan dampak Implikasi Bagi organisasi. Yogyakarta: Univeersitas Sanata Darma.

Yamin, Martinis dan Maisah. 2010. Standarisasi Kinerja Guru. Jakarta: Persada Press.

Yukl, Gary. 2005. Kepemimpinan Dalam Organisasi. Jakarta: PT INDEKS. 